\title{
$\gamma$-Secretase inhibitor enhances antitumour effect of radiation in Notch-expressing lung cancer
}

\author{
H Mizugaki' , J Sakakibara-Konishi", ', Y Ikezawa', J Kikuchi', E Kikuchi', S Oizumi', TP Dang ${ }^{2}$ and M Nishimura' \\ 'First Department of Medicine, Hokkaido University School of Medicine, North 15, West7, Kita-ku, Sapporo 060-8638, Japan; '2Department of Medicine, \\ Division of Hematology/Oncology, University of Virginia, Charlottesville, VA, USA
}

BACKGROUND: Notch receptor has an important role in both development and cancer. We previously reported that inhibition of the Notch3 by $\gamma$-secretase inhibitor (GSI) induces apoptosis and suppresses tumour proliferation in non-small-cell lung cancer. Although radiation is reported to induce Notch activation, little is known about the relationship between radiation and Notch pathway. METHODS: We examined the effect of combining GSI and radiation at different dosing in three Notch expressing lung cancer cell lines. The cytotoxic effect of GSI and radiation was evaluated using MTT assay and clonogenic assay in vitro and xenograft models. Expressions of Notch pathway, mitogen-activated protein kinase (MAPK) pathway and Bcl-2 family proteins were investigated using western blot analysis.

RESULTS: We discovered that the antitumour effect of combining GSI and radiation was dependent on treatment schedule. $\gamma$-Secretase inhibitor administration after radiation had the greatest growth inhibition of lung cancer in vitro and in vivo. We showed that the combination induced apoptosis of lung cancer cell lines through the regulation of MAPK and Bcl-2 family proteins. Furthermore, activation of Notch after radiation was ameliorated by GSI administration, suggesting that treatment with GSI prevents Notch-induced radiation resistance. CONCLUSION: Notch has an important role in lung cancer. Treatment with GSI after radiation can significantly enhance radiationmediated tumour cytotoxicity.

British Journal of Cancer (2012) 106, 1953-1959. doi:I0.1038/bjc.2012.178 www.bjcancer.com

Published online 17 May 2012

(C) 2012 Cancer Research UK

Keywords: Notch; $\gamma$-secretase inhibitor; radiation; apoptosis; non-small-cell lung cancer

Lung cancer is the most common cause of cancer related death in the world, and the incidence is still increasing. Although several therapies are available for advanced disease, they are palliative and the cure rate remains very low for patients. New therapeutic strategies are required to improve the poor prognosis of patients with non-small-cell lung cancer (NSCLC).

Notch receptor is a single-pass transmembrane protein, which regulates cell-fate determination in multi-cellular organisms. In mammals, there are four Notch receptors (Noch1-Notch4) and two families of ligands, Jagged (Jagged1 and -2) and Delta-like (Dll-1, -3 and -4) (Allenspach et al, 2002; Iso et al, 2003). Upon ligand binding, the Notch receptor undergoes a number of proteolytic cleavages. The final cleavage by the $\gamma$-secretase complex releases the Notch intracellular domain (NICD), which forms a nuclear complex with transcription factor CSL (CBF1, Sel, Lag-1) and induces expression of target genes, such as the Hairy and enhancer of split (HES) and Hairy/enhancer of split related with YRPW (HEY) gene family (Weinmaster and Kopan, 2006).

Several studies have highlighted the aberrant activation of Notch pathways in tumourigenesis of many cancers (Das et al, 2004; Curry et al, 2005; Duechler et al, 2005; Reedijk et al, 2005). We have demonstrated that Notch 3 is expressed in $\sim 40 \%$ of NSCLC tumours and that suppression of Notch 3 by dominant negative or $\gamma$-secretase

*Correspondence: J Sakakibara-Konishi; E-mail konishj@med.hokudai.ac.jp Received 22 February 2012; revised 4 April 2012; accepted II April 2012; published online 17 May 2012 inhibitor (GSI) inhibits growth of lung cancer both in vitro and in vivo (Haruki et al, 2005; Konishi et al, 2007). $\gamma$-Secretase inhibitor modulates the Bcl-2 family proteins and downregulates MAPK pathway (Konishi et al, 2007). Our group also reported that Bim, $\mathrm{BH} 3-$ only member of the Bcl-2 family proteins, is necessary for Notch3-dependent apoptosis and that the effect of Notch3 on Bim is through MAPK regulation (Konishi et al, 2010).

Although radiotherapy is routinely used to treat patients with lung cancer, resistance to radiation is one of the major reasons for radiotherapy failure in NSCLC. While many factors have been proven contributing to this observation, radiation has been shown to activate Notch in breast cancer and glioma. Given the role of Notch signalling in oncogenesis, these observations suggest that Notch represents a mechanism of radioresistance (Phillips et al, 2006; Wang et al, 2010).

In this study, we demonstrated the enhanced antitumour effect of GSI after radiation in Notch expressing lung cancer cell lines in vitro and in vivo. We also provide evidence that the observed antitumour effect involves Notch pathway. The mechanism involves apoptosis through the regulation of MAPK and Bcl-2 family proteins. Thus, our findings will help define a new strategy in modulating radiation therapy to enhance clinical efficacy in the treatment of patients with NSCLC.

\section{MATERIALS AND METHODS}

\section{Cell lines and inhibitors}

HCC2429 was established as previously described (Dang et al, 2000). The NSCLC cell lines, H460, A549 and H1395 were obtained 
from American Type Culture Collection (Manassas, VA, USA). Cell lines were maintained in RPMI supplemented with $10 \%$ foetal calf serum at $37{ }^{\circ} \mathrm{C}$ in a humid environment in $5 \% \mathrm{CO}_{2} \cdot \gamma$-Secretase inhibitor I (in vitro) and GSI XX (in vitro, in vivo) were obtained from Calbiochem (San Diego, CA, USA).

\section{MTT proliferation assay}

HCC2429 at 10000 cells per well, H460 and H1395 at 500 cells per well were seeded into a 96-well plate and incubated overnight. HCC2429 and H460 were shown previously to have high Notch3 expression, whereas H1395 did not express Notch (Konishi et al, 2007). The cells were treated with GSI I and radiation simultaneously, radiation at $24 \mathrm{~h}$ after GSI I or GSI I at $24 \mathrm{~h}$ post-radiation. Treated cells were then incubated for 8 days. The MTT assay was performed to according to manufacturer's recommendation. The absorption was determined at $560 \mathrm{~nm}$ using the microplate reader (Varioskan Flash; Thermo Fisher Scientific, Lafayette, CO, USA).

\section{Clonogenic assay}

HCC2429 at 5000 cells per well, H460 and H1395 at 2000 cells per well were plated on 6 -well plate and were then irradiated with 0 to $4 \mathrm{~Gy}$ as indicated after an overnight incubation. $\gamma$-Secretase inhibitor I at varying doses was added at $24 \mathrm{~h}$ after radiation and cells were incubated for 8 days. The cells were then fixed and stained for $1 \mathrm{~min}$ with $0.5 \%$ crystal violet in methanol. The number of colonies was counted manually. Survival fraction was calculated using the following formula: mean colony counts/cells inoculated $\times$ plating efficiency (PE). PE was defined as: mean colony counts/cells inoculated for unirradiated controls, as previously described (Cao et al, 2004).

\section{Quantification of interaction of combination}

Combination index (CI) for the GSI and radiation was described previously (Chou and Talalay, 1984; Gorodetsky et al, 1998). Accordingly, CI was calculated as follows:

$$
\mathrm{CI}=D / \mathrm{Dx}+C / \mathrm{Cx}+(D / \mathrm{Dx} \times C / \mathrm{Cx}) .
$$

Where $\mathrm{Dx}$ is the dose of radiation and Cx is the dose of GSI that yields a selected level of survival $(x)$ when each agent is used alone. $D$ is the dose of radiation and $C$ is the dose of GSI that yields the same survival $(x)$ when both treatments were combined. The level of survival selected to evaluate each set of combined treatments is lower than the survival following radiation alone. Combination index values are smaller than, equal to or greater than 1 represent supra-additive, additive and sub-additive effects of the combined treatment, respectively.

\section{Apoptosis assays}

HCC2429 and H460 were plated onto 6-well plates at the density of $1 \times 10^{6}$ cells per well and $3 \times 10^{5}$ cells per well respectively, incubated overnight, and subsequently treated with GSI I $1 \mu \mathrm{m}$ for HCC2429 and $9 \mu \mathrm{m}$ for H460 $24 \mathrm{~h}$ after 8 Gy of radiation. HCC2429 and H460 were then incubated for 24 and $48 \mathrm{~h}$, respectively. The cells were stained with FITC-conjugated Annexin V and propidium iodide (PI), using Annexin V-FITC Apoptosis Detection kit and according to manufacturer's recommendation (Calbiochem). The percentage of apoptotic cells was determined using a flow cytometry (BD FACSCalibur; Becton, Dickinson and Company, Franklin Lakes, NJ, USA).

\section{Antibodies and western blot analysis}

Notch3 was detected using a rabbit polyclonal antibody from Allele Biotechnology and Pharmaceuticals, Inc. (San Diego, CA, USA) at $1: 500$. Notch 1 was detected using a mouse monoclonal antibody from Sigma-Aldrich Corp. (St Louis, MO, USA) at 1:500. The rabbit antibodies to HES1 and HEY1 were obtained from Santa Cruz Biotechnology, Inc. (Santa Cruz, CA, USA). The rabbit antibodies to Bcl-xL, phosphor-Bcl-2 (p-Bcl-2), Bcl-2, extracellular signal-regulated kinase (ERK), p-ERK, AKT, p-AKT and poly (ADP-ribose) polymerase (PARP) were obtained from Cell Signaling Technology, Inc. (Danvers, MA, USA). Bim antibody was obtained from Sigma-Aldrich Corp. The band intensity was demonstrated by quantitative densitometric analysis using $\mathrm{NIH}$ Image Ver1.62 software (NIH, Bethesda, MD, USA). Standardisation was performed with actin measured in the same blots with anti-actin antibody (A-2066, Sigma-Aldrich Corp.). Quantifications were shown by the ratios of treated protein expression/untreated protein expression.

\section{In vivo tumourigenicity}

All animal husbandry and experiments were performed under a protocol approved by Institutional Animal Care Committee at Hokkaido University School of Medicine. H460 and A549 at $1.0 \times 10^{6}$ cells were diluted in $100 \mu \mathrm{l}$ of PBS and injected subcutaneously into right posterior legs of athymic, 5-week-old, female nude mice $(n u+/ n u+)$. When the tumours were palpable, the mice were randomly assigned to the radiation group, the GSI group, the combination group or the control group. Each group consisted of five mice. The mice in the radiation alone group received $8 \mathrm{~Gy}$ of radiation at day 1 and 8 . The radiation was administered to the tumour with the remainder of the body shielded with lead. In the GSI group, $200 \mu \mathrm{g} \mathrm{kg}^{-1}$ GSI XX was administered by i.p. at day 2, 3, 4 and 9, 10, 11, as previously described (Tanaka et al, 2009; Konishi et al, 2010). The combination group received both GSI XX and radiation in similar schedule. The tumours were then measured every 2 days using a digital caliper. Tumour volume (TV) was determined using the formula: $\mathrm{TV}=($ Length $) \times($ Width $) \times($ Height $) / 2($ Cao et al, 2004 $)$. Tumour growth rate (\%TV) on day $\mathrm{X}$ was calculated as: (TV on day X/TV on day1) $\times 100$, as previously described (Konishi et al, 2010). Some tumours were resected on day 15 and the expression of NICD3 was determined by western blot analysis.

\section{Statistical analysis}

Determination of significance between the control and observation arms of both in vitro and in vivo assays was analysed using the non-parametric Mann-Whitney $U$ test. Statistical significance was established at the $P$ value $<0.05$. Calculations were performed using SPSS, version 11.0.1 (SPSS Inc., Chicago, IL, USA).

\section{RESULTS}

\section{Treatment with GSI at $24 \mathrm{~h}$ after radiation enhanced growth inhibition of lung cancer in vitro}

To determine whether the combining GSI and radiation can inhibit lung cancer proliferation, we treated Notch expressing lung cancer cell lines, HCC2429 and H460 with increasing dose of GSI and radiation. Cell viability of both cell lines was determined using the MTT assay. Neither concurrent treatment schedule nor radiation after GSI I administration had a significant impact on tumour proliferation compared with single treatment with GSI I alone (0 Gy) (Figure 1A). In contrast, when GSI I was administrated after radiation, there was a significant decrease in $\mathrm{IC}_{50}$ of GSI I compared to treatment with GSI I alone (0 Gy) in HCC2429 and H460 (Figure 1B and Supplementary Table 1). Clonogenic assay was performed to confirm the results of the MTT assay. This treatment schedule resulted in greater suppression in colony formations compared with radiation alone (Figure 1C). On the other hand, in H1395, which does not express Notch, no difference 
A

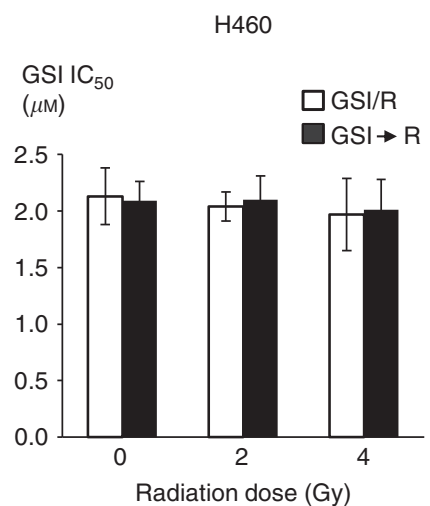

C

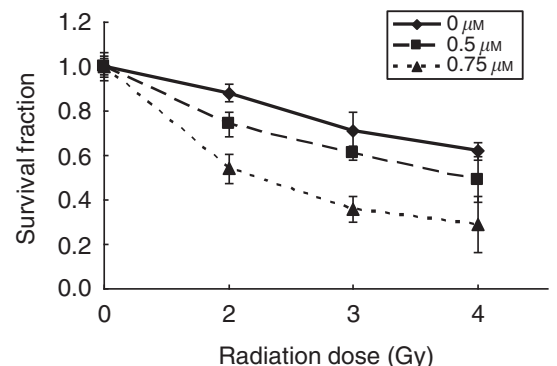

B

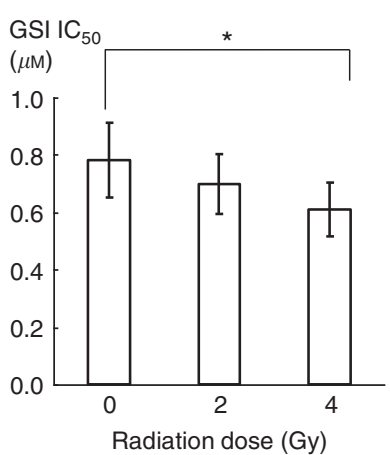

$\mathrm{H} 460$

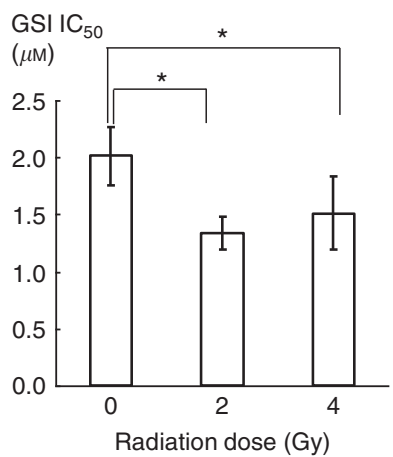

$\mathrm{H} 1395$

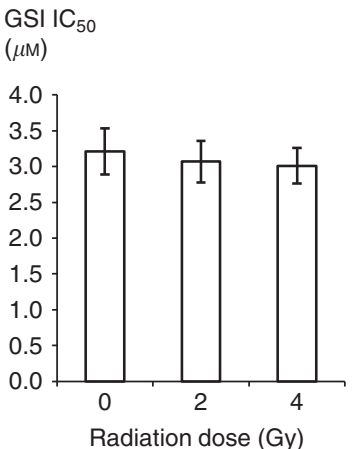

$\mathrm{H} 460$

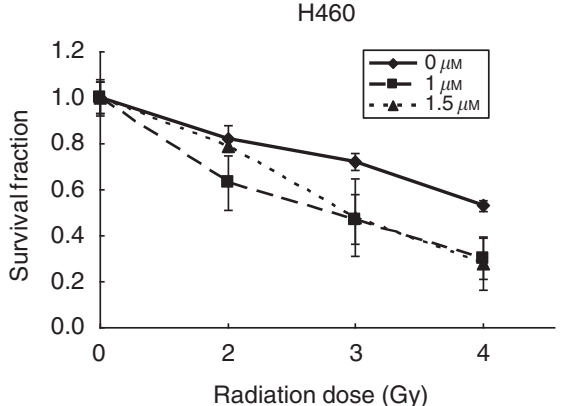

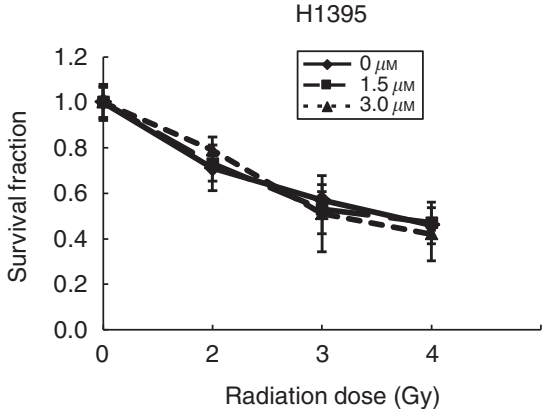

Figure I GSI after radiation suppressed proliferation of lung cancer. (A) Comparison of $\mathrm{IC}_{50}$ values in the different treatment schedule in the MTT proliferation assay. Neither concurrent treatment schedule nor radiation after GSI I administration had a significant impact on tumour proliferation compared with GSI I alone (0 Gy). Plated cells were treated with GSI I and radiation simultaneously or radiation at $24 \mathrm{~h}$ after $\mathrm{GSI}$ I administration $(n=5)$. Treated cells were incubated for 8 days. GSI/R: concurrent treatment schedule. GSI $\rightarrow$ R: radiation after GSI I administration. (B) Comparison of IC 50 in GSI I after radiation. Plated cells were treated with GSI I at varying doses at $24 \mathrm{~h}$ after radiation. $I_{50}$ was less for combined therapy than for GSI I alone in both HCC2429 and H460 cell lines $(n=5)$. *P<0.05. On the contrary, IC 50 was not different between GSI alone and combination in HI 395. (C) GSI I after radiation decreased clonogenic survival in $\mathrm{HCC} 2429$ and $\mathrm{H} 460$, but not in $\mathrm{HI} 395(n=3)$. Cells were plated overnight and then exposed to radiation with 0 to 4 Gy as indicated. GSI I at varying doses was added at $24 \mathrm{~h}$ after radiation and then cells were incubated for 8 days.

Table I Combination index $(\mathrm{Cl})$ with respect to survival fraction of HCC2429 and H460 cells exposed to GSI I after radiation

\begin{tabular}{|c|c|c|c|c|c|c|c|}
\hline \multicolumn{4}{|c|}{ HCC2429 } & \multicolumn{4}{|c|}{$\mathrm{H} 460$} \\
\hline $\begin{array}{c}\text { Survival } \\
\text { fraction } \\
(\%)\end{array}$ & $\begin{array}{l}\text { Radiation } \\
\left(D^{\mathbf{a}}\right)(G y)\end{array}$ & $\begin{array}{c}\text { GSI } \\
\left(\mathbf{C}^{\mathbf{a}}\right) \mu \mathrm{M}\end{array}$ & $\mathrm{Cl}^{\mathrm{b}}$ & $\begin{array}{c}\text { Survival } \\
\text { fraction } \\
(\%)\end{array}$ & $\begin{array}{l}\text { Radiation } \\
\left(D^{\mathbf{a}}\right)(G y)\end{array}$ & $\begin{array}{c}\text { GSI } \\
\left(\mathbf{C}^{\mathbf{a}}\right) \mu \mathrm{M}\end{array}$ & $\mathrm{Cl}^{\mathrm{b}}$ \\
\hline 50 & 2.0 & 0.47 & 0.96 & 50 & 2.0 & 1.29 & 0.93 \\
\hline 50 & 3.0 & 0.28 & 1.00 & 50 & 3.0 & 0.98 & 1.0 \\
\hline 50 & 4.0 & 0.20 & 1.10 & 50 & 4.0 & 0.68 & 1.2 \\
\hline 25 & 2.0 & 0.56 & 0.78 & 25 & 2.0 & 1.64 & $0 . \varepsilon$ \\
\hline 25 & 3.0 & 0.45 & 0.86 & 25 & 3.0 & 1.56 & 0.9 \\
\hline 25 & 4.0 & 0.31 & 0.87 & 25 & 4.0 & 1.46 & 1.10 \\
\hline 10 & 2.0 & 0.66 & 0.66 & 10 & 2.0 & 2.43 & 0.84 \\
\hline 10 & 3.0 & 0.65 & 0.76 & 10 & 3.0 & 2.26 & 0.91 \\
\hline 10 & 4.0 & 0.64 & 0.86 & 10 & 4.0 & 1.98 & 0.94 \\
\hline
\end{tabular}

Abbreviations: $\mathrm{Cl}=$ combination index; $\mathrm{GSI}=\gamma$-secretase inhibitor. ${ }^{\mathrm{a}} \mathrm{C}$ and $\mathrm{D}$ were obtained from the survival fraction curve (Figure IC). ${ }^{\mathrm{b}} \mathrm{Cl}$ was calculated for different levels of survival fraction according to Equation I.

between single treatment and combination was observed in $\mathrm{IC}_{50}$ and colony formations (Figure $1 \mathrm{~B}$ and $\mathrm{C}$ and Supplementary Table 1), suggesting that combination is only effective in Notch expressing cell lines. By determining the CI values of GSI I after radiation in HCC2429 and H460, we noted supra-additive or additive effects of combination in the most set of combining treatment (Table 1). Therefore, this sequential treatment schedule was employed in all of the following experiments.

\section{GSI prevents radiation-dependent Notch activation}

When HCC2429 and H460 were treated with GSI I alone, the expression of NICD in both cell lines was decreased in a dose-dependent manner (Figure 2A). To investigate the effect of radiation on Notch pathway, the expressions of NICD1, NICD3 and target genes, HES1 and HEY1 were assessed after cells were irradiated at 2 and $4 \mathrm{~Gy}$, respectively. In HCC2429, the expression of NICD1 was upregulated at $24 \mathrm{~h}$ after radiation and this upregulation was observed up to $48 \mathrm{~h}$ following radiation, whereas the expression of NICD3 was unchanged. Notch 1 mRNA was also upregulated after radiation, suggesting that radiation induces transcripts of Notch1 (Supplementary Figure 1). In H460, in which the baseline expression of Notch3 level is lower, NICD3 expression was increased at 24 and $48 \mathrm{~h}$ after radiation and the expression of NICD1 was not induced by radiation (Figure 2B). Notch3 mRNA was upregulated after radiation in $\mathrm{H} 460$ (Supplementary Figure 1). HEY1 expression was upregulated in both cell lines at $48 \mathrm{~h}$ after radiation compared with control. Then, we examined NICD1 and NICD3 expression when cells were treated with GSI I, radiation or the combination treatment. Radiationinduced NICD1 upregulation was ameliorated by the combination in HCC2429. Radiation-induced NICD3 enhancement was also reduced by the combination in $\mathrm{H} 460$ (Figure 2C).

\section{Addition of GSI enhances radiation-induced apoptosis}

To examine whether addition of GSI following radiation can induce apoptosis compared either treatment alone, we treated HCC2429 and H460 with GSI I after radiation and determined the proportion of apoptotic cells using Annexin V and PI and flow 
A

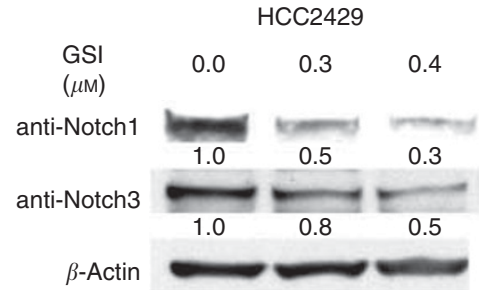

B

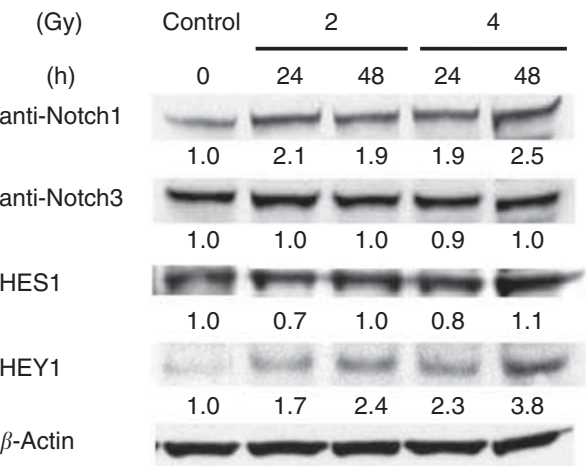

C

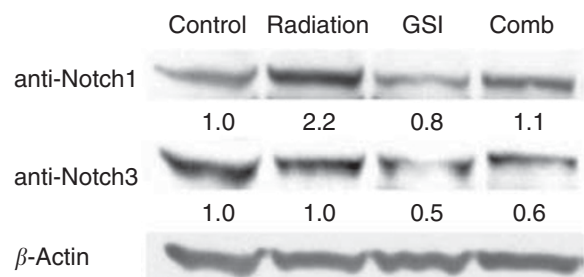

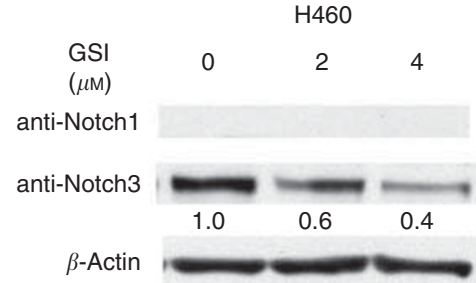

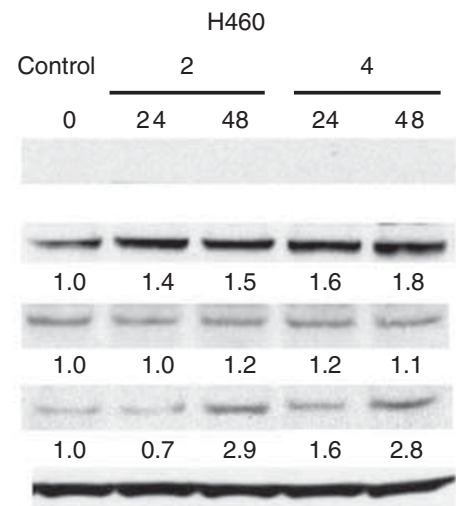

$\mathrm{H} 460$

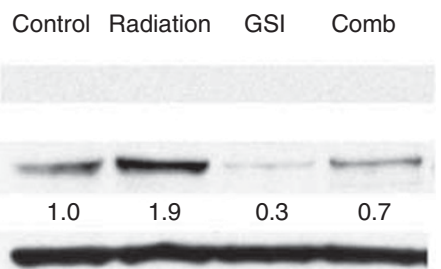

Figure 2 Combination and either GSI or radiation alone regulated the Notch pathway. (A) GSI suppressed Notch intracellular domain (NICD) expression in a dose-dependent manner. GSI I downregulated NICDI and NICD3 in HCC2429, whereas NICD3 in H460. (B) Radiation upregulated NICDI, but not NICD3 in HCC2429, whereas NICD3 in H460 at $24 \mathrm{~h}$ after radiation (2 or $4 \mathrm{~Gy}$ ). The downstream Notch target gene, HEY I, was also upregulated at $48 \mathrm{~h}$ after radiation. (C) Radiation-induced Notch upregulation was ameliorated by the combination. Standardisation was performed with actin measured in the same blots with anti-actin antibody. Quantifications were shown by the ratios of treated protein expression/untreated protein expression.

cytometry (Figure 3A). Either treatment induced apoptosis. However, the combination increased apoptotic cells two or three fold compared with either treatment alone (Figure 3B). When GSI $\mathrm{XX}$ was used, we also noted the higher induction of apoptosis in NSCLC cell lines (HCC2429, H460 and A549) with radiation compared with either treatment alone (Supplementary Figure 2).

\section{Combination alters p-ERK, anti-apoptotic proteins, and pro-apoptotic proteins}

As Notch has been shown to crosstalk with the epidermal growth factor receptor pathway (Haruki et al, 2005), we assessed the expression of phospo-ERK, a member of the MAPK family and phospho-AKT. The combination reduced the expression of p-ERK compared with either GSI I or radiation alone (Figure 4A). Although several studies have shown the crosstalk between Notch pathway and phosphatidylinositol 3-kinase (PI3K)/AKT pathway (Wang et al, 2007; Meng et al, 2009), we observed no effect on p-AKT level in any of the treatments (Figure 4A).

To confirm the effect of the combination on apoptosis, we examined the expression of the Bcl-2 family proteins. We found that the combination reduces levels of anti-apoptotic proteins, p-Bcl-2 and Bcl-xL, and increases pro-apoptotic protein Bim, compared with either GSI I or radiation alone in both cell lines. Furthermore, cleaved PARP was induced in single treatment and combination in both cell lines (Figure 4B).

\section{Combination enhances antitumour activity in vivo}

To determine the effect of combining GSI with radiation in vivo, we utilised a xenograft model. We previously have shown that GSI suppressed tumour growth of Notch expressing lung cancer cell lines, $\mathrm{H} 460$ and A549 in vivo (Konishi et al, 2007). The scheduling of radiation and GSI was outlined in Figure 5A based on our previous findings (Konishi et al, 2007; Tanaka et al, 2009). The radiation was given on days 1 and 8 at 8 Gy per dose, and GSI XX $200 \mu \mathrm{g} \mathrm{kg}^{-1}$ was administered by i.p. injection on days $2-4$ and $9-11$. We noted a significant delay in growth of tumours in the combination group compared with either of the treatments alone (Figure 5B). Some tumours were resected on day 15 for molecular analysis. Consistent with our in vitro findings, expression of activated NICD3 was enhanced in tumours treated with radiation, and this activation was mitigated by the addition of GSI (Figure 5C). This observation supports our hypothesis that induction of Notch pathway by radiation is one mechanism of resistance to radiation and can be ameliorated by the addition of GSI. Intestinal toxicity has been major concern in using GSI owing to the loss of intestinal crypts cells and hyperplasia of intestinal goblet cells (Guilmeau et al, 2010). Others reported the observed gut toxicity from GSI was mitigated with intermittent dosing (Tamman et al, 2009). We stained intestine of treated mice with periodic acid schiff to examine the intestinal toxicity of GSI. No increase of intestinal goblet cells was seen among treated mice compared with controls (data not shown). 
A

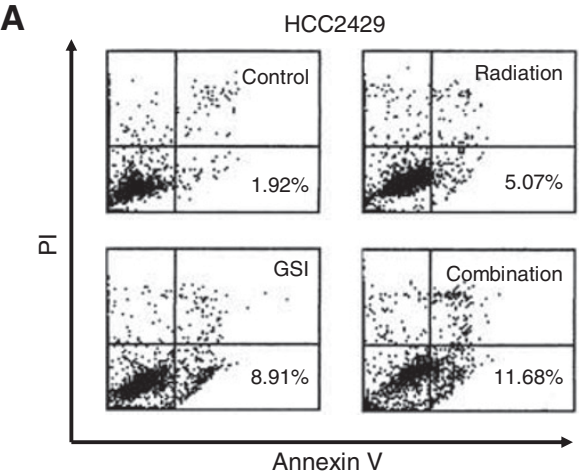

B

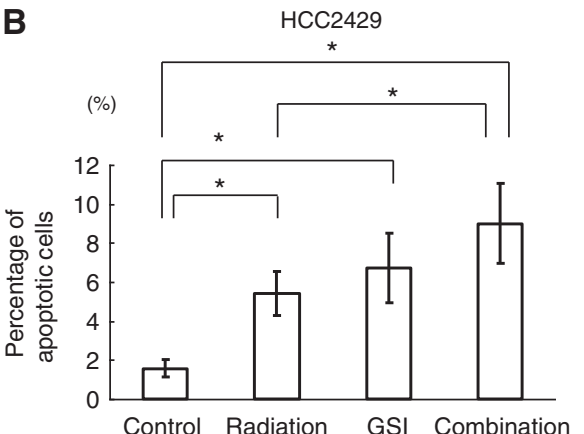

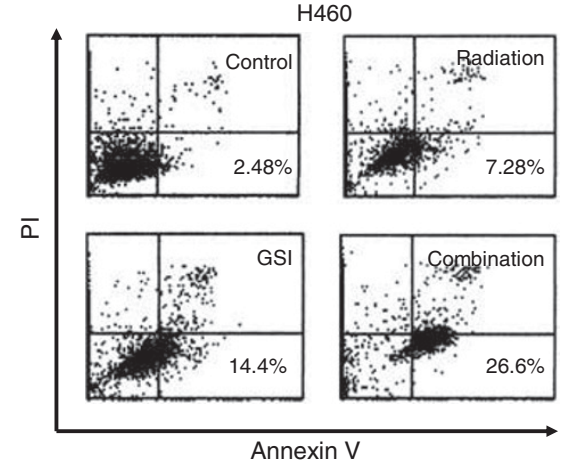

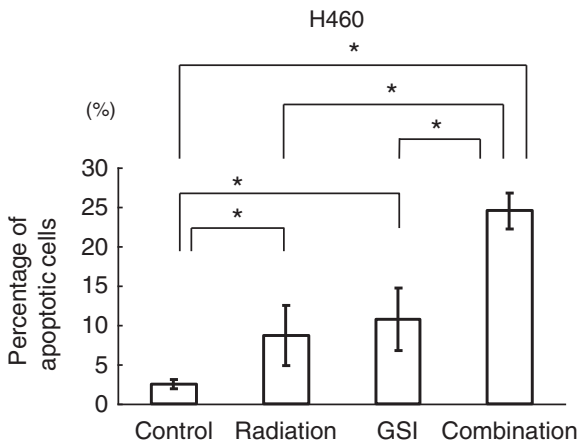

Figure 3 Combination treatment induced apoptosis of lung cancer. Cells were treated with GSI I ( I $\mu \mathrm{m}$ in HCC2429 and $9 \mu \mathrm{m}$ in H460) at $24 \mathrm{~h}$ after $8 \mathrm{~Gy}$ of radiation. The percentage of apoptotic cells was measured using Annexin $\vee$ and propidium iodide (PI) with flow cytometry. (A) Representative data of four independent experiments on HCC2429 and H460. (B) Mean percentage of apoptotic cells. Combination therapy induced significantly higher apoptosis in HCC2429 and $\mathrm{H} 460$ cells $(n=4)$. $* P<0.05$.

A



B

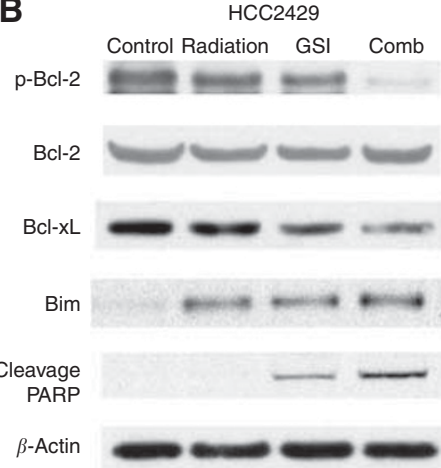

Figure 4 Apoptosis was induced through the MAPK pathway and $\mathrm{Bcl}-2$ family proteins by the combination of GSI and radiation. Cells were treated with GSI I ( I $\mu \mathrm{M}$ in HCC2429 and $9 \mu \mathrm{M}$ in $\mathrm{H} 460)$ at $24 \mathrm{~h}$ after 8 Gy of radiation. (A) Combination therapy downregulated p-ERK, but had no effect on p-AKT in either HCC2429 or H460. (B) Combination therapy downregulated anti-apoptotic proteins, $\mathrm{p}-\mathrm{Bcl}-2$ and $\mathrm{BCl}-\mathrm{xL}$, and upregulated apoptotic proteins, Bim and cleaved PARP, in both HCC2429 and $\mathrm{H} 460$.
Furthermore, no body weight loss was encountered (data not shown), indicating that all treatments, including the combination therapy was well tolerated.

\section{DISCUSSION}

Radiation therapy is the primary treatment for patients with locally advanced lung cancer. Although it is very effective in local control, majority of patients will die of their disease, suggesting that further studies are needed to better understand the mechanisms of radiation resistance and to develop new strategies to improve radiation-dependent tumour cytotoxicity.

The phenotypic outcome of Notch signalling is often contextdependent. In lung cancer, Notch1 was known to suppress tumour proliferation under normoxia, but in hypoxia, it had a converse role in tumour promotion (Chen et al, 2007). Moreover, the specific role of each individual Notch receptor in radiation is not fully understood, but our present observation that Notch1, but not Notch3, was enhanced by radiation in HCC2429 also suggests that the biological function of Notch depends on treatment context, suggesting that targeting specific Notch receptor may lead to better outcome by preventing unnecessary toxicity.

In breast cancer, Notch signalling is activated after radiation, suggesting that activation of this oncogenic pathway is a mechanism of radiation resistance (Phillips et al, 2006). We hypothesised that Notch activation by radiation has radioprotective role in lung cancer, this phenomenon can be prevented by the use of Notch inhibitors after radiation. In our study, we also showed that radiation-induced Notch activation, which was mitigated by the administration of GSIs, supporting our hypothesis and providing a rationale for the sequential treatment schedule.

Enhanced induction of PARP and reduction of pro-survival proteins, such as $\mathrm{p}-\mathrm{Bcl}-2$ and $\mathrm{Bcl}-\mathrm{xL}$, by the combination therapy 



Figure 5 Combination therapy inhibited tumour growth of lung cancer in vivo. (A) Treatment schedule in vivo. $\mathrm{H} 460$ and A549 at I.0 $\times 10^{6}$ cells were inoculated subcutaneously into right posterior legs of nude mice. Treatment was initiated when tumours were palpable. Mice were treated with $200 \mu \mathrm{g} \mathrm{kg}^{-}$ GSI XX injected intraperitoneally 3 days per week after 8 Gy of radiation once a week. Tumour size was measured every 2 days. Some tumours were removed on day 15 and the expression of NICD3 was examined by western blot analysis. (B) Combination treatment showed the significant delay of tumour growth, compared with control or single treatment alone $(n=5)$. (C) NICD3 expression was upregulated in H460 and A549 tumour treated with radiation. In contrast, combination therapy reduced NICD3 expression.

suggested that the observed antitumour effect is mediated through induction of apoptosis. Our findings are compatible with the other reports that GSI or radiation activates the apoptosis pathway, including Bcl-2 family (Konishi et al, 2007; Han et al, 2009; Zhuang et al, 2009). Some studies have shown that Notch regulated the AKT pathway in several cancers (Liu et al, 2006; Meng et al, 2009; Efferson et al, 2010), but expression of p-AKT was unchanged in our study, suggesting that the crosstalks between Notch and other oncogenic pathways are context-dependent.

Cancer stem cells (CSCs) are a small population of cells that are responsible for tumour maintenance and spreading (Reya et al, 2001; Lobo et al, 2007). CSCs in lung cancer have been isolated and functions have been described in several reports (Ho et al, 2007; Eramo et al, 2008). CSCs are further reported to contribute to resistance of chemotherapy or radiation (Phillips et al, 2006; Ho et al, 2007; Eramo et al, 2008; Diehn et al, 2009; Rutella et al, 2009). Notch pathway was activated in several types of CSCs, including colon cancer, breast cancer and glioma (Dontu et al, 2003; Purow et al, 2005; Sikandar et al, 2010). For example, radiation appeared to enhance Notch pathway in both breast cancer (CD24-/low/ $\left.\mathrm{CD}_{4} 4^{+}\right)$and glioma $\left(\mathrm{CD} 133^{+}\right)$stem-like cells. The activation of these cells was accompanied by radioresistance (Phillips et al, 2006; Wang et al, 2010). We did not examine how the combination therapy affects lung CSCs, as it is unclear that similar markers such as CD133 or CD44 can be used as markers for lung CSC. However, our study suggests GSI prevents the induction of CSCs by radiation, leading to the reduction of tumour growth.

In vivo, we observed a statistically significant delay of tumour growth in mice with combination therapy. GSI inhibited NICD both in vitro and in vivo and might get biochemical inhibition at much lower doses used in vivo than used in vitro. This suggests to us that the microenvironment contributes to the observable effect. For example, the Notch ligand DLL4 has a critical role in the angiogenesis (Ridgway et al, 2006; Scehnet et al, 2007) and GSI has been shown to inhibit tumour growth through preventing DLL4dependent angiogenesis (Li et al, 2011). Furthermore, hypoxic tumour environment induces radiation resistance (Wilson and Hay, 2011). Notch 1 was activated under hypoxia in lung cancer cell lines and GSI-induced apoptosis of these cells (Chen et al, 2007; Eliasz et al, 2010). From these observations and our data, GSI may not only inhibit tumour cells but also tumour microenvironment, which promotes tumour survival.

In summary, our data provided the evidence that the addition of GSI enhanced the cytotoxicity of radiation in lung cancer both in vitro and in vivo. Because of the role of Notch signalling in tumour hypoxia and CSCs, the radiation-dependent Notch activation likely represents a mechanism of radioresistence. Further studies are needed to ascertain our hypothesis. Nevertheless, our study provides compelling evidence that combining GSI and radiation represents a rational strategy for the treatment of patients with NSCLC.

\section{ACKNOWLEDGEMENTS}

We thank Dr T Takeshima (Graduate School of Medicine, Department of Radiology, Hokkaido University), J Moriya (Department of Surgical Pathology, Hokkaido University Hospital) and S Shoji (First Department of Medicine, Hokkaido University School of Medicine) for their special support and experimental assistance.

\section{Conflict of interest}

The authors declare no conflict of interest.

Supplementary Information accompanies the paper on British Journal of Cancer website (http://www.nature.com/bjc) 


\section{REFERENCES}

Allenspach EJ, Maillard I, Aster JC, Pear WS (2002) Notch signaling in cancer. Cancer Biol Ther 1(5): 466-476

Cao C, Mu Y, Hallahan DE, Lu B (2004) XIAP and survivin as therapeutic targets for radiation sensitization in preclinical models of lung cancer. Oncogene 23(42): 7047-7052

Chen Y, De Marco MA, Graziani I, Gazdar AF, Strack PR, Miele L, Bocchetta M (2007) Oxygen concentration determines the biological effects of NOTCH-1 signaling in adenocarcinoma of the lung. Cancer Res 67(17): 7954-7959

Chou TC, Talalay P (1984) Quantitative analysis of dose-effect relationships: the combined effects of multiple drugs or enzyme inhibitors. Adv Enzyme Regul 22: 27-55

Curry CL, Reed LL, Golde TE, Miele L, Nickoloff BJ, Foreman KE (2005) Gamma secretase inhibitor blocks Notch activation and induces apoptosis in Kaposi's sarcoma tumor cells. Oncogene 24(42): 6333-6344

Dang TP, Gazdar AF, Virmani AK, Sepetavec T, Hande KR, Minna JD, Roberts JR, Carbone DP (2000) Chromosome 19 translocation, overexpression of Notch3, and human lung cancer. J Natl Cancer Inst 92(16): 1355-1357

Das I, Craig C, Funahashi Y, Jung KM, Kim TW, Byers R, Weng AP, Kutok JL, Aster JC, Kitajewski J (2004) Notch oncoproteins depend on gamma-secretase/presenilin activity for processing and function. J Biol Chem 279(29): 30771-30780

Diehn M, Cho RW, Lobo NA, Kalisky T, Dorie MJ, Kulp AN, Qian D, Lam JS, Ailles LE, Wong M, Joshua B, Kaplan MJ, Wapnir I, Dirbas FM, Somlo G, Garberoglio C, Paz B, Shen J, Lau SK, Quake SR, Brown JM, Weissman IL, Clarke MF (2009) Association of reactive oxygen species levels and radioresistance in cancer stem cells. Nature 458(7239): 780-783

Dontu G, Al-Hajj M, Abdallah WM, Clarke MF, Wicha MS (2003) Stem cells in normal breast development and breast cancer. Cell Prolif 36(Suppl 1): 59-72

Duechler M, Shehata M, Schwarzmeier JD, Hoelbl A, Hilgarth M, Hubmann R (2005) Induction of apoptosis by proteasome inhibitors in B-CLL cells is associated with downregulation of CD23 and inactivation of Notch2. Leukemia 19(2): 260-267

Efferson CL, Winkelmann CT, Ware C, Sullivan T, Giampaoli S, Tammam J, Patel S, Mesiti G, Reilly JF, Gibson RE, Buser C, Yeatman T, Coppola D, Winter C, Clark EA, Draetta GF, Strack PR, Majumder PK (2010) Downregulation of Notch pathway by a gamma-secretase inhibitor attenuates AKT/mammalian target of rapamycin signaling and glucose uptake in an ERBB2 transgenic breast cancer model. Cancer Res 70(6): 2476-2484

Eliasz S, Liang S, Chen Y, De Marco MA, Machek O, Skucha S, Miele L, Bocchetta M (2010) Notch-1 stimulates survival of lung adenocarcinoma cells during hypoxia by activating the IGF-1R pathway. Oncogene 29(17): 2488-2498

Eramo A, Lotti F, Sette G, Pilozzi E, Biffoni M, Di Virgilio A, Conticello C, Ruco L, Peschle C, De Maria R (2008) Identification and expansion of the tumorigenic lung cancer stem cell population. Cell Death Differ 15(3): 504-514

Gorodetsky R, Levy-Agababa F, Mou X, Vexler AM (1998) Combination of cisplatin and radiation in cell culture: effect of duration of exposure to drug and timing irradiation. Int J Cancer 75(4): 635-642

Guilmeau S, Flandez M, Mariadason JM, Augenlicht LH (2010) Heterogeneity of Jagged1 expression in human and mouse intestinal tumors: implications for targeting Notch signaling. Oncogene 29(7): 992-1002

Han Y, Wang Y, Xu HT, Yang LH, Wei Q, Liu Y, Zhang Y, Zhao Y, Dai SD, Miao Y, Yu JH, Zhang JY, Li G, Yuan XM, Wang EH (2009) X-radiation induces non-small-cell lung cancer apoptosis by upregulation of Axin expression. Int J Radiat Oncol Biol Phys 75(2): 518-526

Haruki N, Kawaguchi KS, Eichenberger S, Massion PP, Olson S, Gonzalez A, Carbone DP, Dang TP (2005) Dominant-negative Notch3 receptor inhibits mitogen-activated protein kinase pathway and the growth of human lung cancers. Cancer Res 65(9): 3555-3561

Ho MM, Ng AV, Lam S, Hung JY (2007) Side population in human lung cancer cell lines and tumors is enriched with stem-like cancer cells. Cancer Res 67(10): 4827-4833

Iso T, Kedes L, Hamamori Y (2003) HES and HERP families: multiple effectors of the Notch signaling pathway. J Cell Physiol 194(3): 237-255

Konishi J, Kawaguchi KS, Vo H, Haruki N, Gonzalez A, Carbone DP, Dang TP (2007) Gamma-secretase inhibitor prevents Notch3 activation and reduces proliferation in human lung cancers. Cancer Res 67(17): 8051-8057

Konishi J, Yi F, Chen X, Vo H, Carbone DP, Dang TP (2010) Notch3 cooperates with the EGFR pathway to modulate apoptosis through the induction of bim. Oncogene 29(4): 589-596
Li JL, Sainson RCA, Oon CE, Turley H, Leek R, Sheldon H, Bridges E, Shi W, Snell C, Bowden ET, Wu H, Chowdhury PS, Russll AJ, Montgomery CP, Poulsom R, Harris AL (2011) DLL4-Notch signaling mediated tumor resistance to anti-VEGF therapy in vivo. Cancer Res 71(18): 6073-6083

Liu ZJ, Xiao M, Balint K, Smalley KS, Brafford P, Qiu R, Pinnix CC, Li X, Herlyn M (2006) Notch1 signaling promotes primary melanoma progression by activating mitogen-activated protein kinase/phosphatidylinositol 3-kinase-Akt pathways and up-regulating $\mathrm{N}$-cadherin expression. Cancer Res 66(8): 4182-4190

Lobo NA, Shimono Y, Qian D, Clarke MF (2007) The biology of cancer stem cells. Annu Rev Cell Dev Biol 23: 675-699

Meng RD, Shelton CC, Li YM, Qin LX, Notterman D, Paty PB, Schwartz GK (2009) gamma-Secretase inhibitors abrogate oxaliplatin-induced activation of the Notch-1 signaling pathway in colon cancer cells resulting in enhanced chemosensitivity. Cancer Res 69(2): 573-582

Phillips TM, McBride WH, Pajonk F (2006) The response of CD24(-/low)/CD44+ breast cancer-initiating cells to radiation. J Natl Cancer Inst 98(24): 1777-1785

Purow BW, Haque RM, Noel MW, Su Q, Burdick MJ, Lee J, Sundaresan T, Pastorino S, Park JK, Mikolaenko I, Maric D, Eberhart CG, Fine HA (2005) Expression of Notch-1 and its ligands, Delta-like-1 and Jagged-1, is critical for glioma cell survival and proliferation. Cancer Res 65(6): 2353-2363

Reedijk M, Odorcic S, Chang L, Zhang H, Miller N, McCready DR, Lockwood G, Egan SE (2005) High-level coexpression of JAG1 and NOTCH1 is observed in human breast cancer and is associated with poor overall survival. Cancer Res 65(18): 8530-8537

Reya T, Morrison SJ, Clarke MF, Weissman IL (2001) Stem cells, cancer, and cancer stem cells. Nature 414(6859): 105-111

Ridgway J, Zhang G, Wu Y, Stawicki S, Liang WC, Chanthery Y, Kowalski J, Watts RJ, Callahan C, Kasman I, Singh M, Chien M, Tan C, Hongo JAS, Sauvage F, Plowman G, Yan M (2006) Inhibition of DLL4 sinaling inhibits tumor growth by deregulating angiogenesis. Nature 444(7122): 1083-1087

Rutella S, Bonanno G, Procoli A, Mariotti A, Corallo M, Prisco MG, Eramo A, Napoletano C, Gallo D, Perillo A, Nuti M, Pierelli L, Testa U, Scambia G, Ferrandina G (2009) Cells with characteristics of cancer stem/ progenitor cells express the CD133 antigen in human endometrial tumors. Clin Cancer Res 15(13): 4299-4311

Scehnet JS, Jiang W, Kumar SR, Krasnoprev V, Trindade A, Benedito R, Djokovic D, Borgers C, Ley EJ, Duarte A, Gill PS (2007) Inhibition of Dll4-mediated signaling induces proliferation of immature vessels and results in poor tissue prefusion. Blood 109(11): 4753-4760

Sikandar SS, Pate KT, Anderson S, Dizon D, Edwards RA, Waterman ML, Lipkin SM (2010) NOTCH signaling is required for formation and selfrenewal of tumor-initiating cells and for repression of secretory cell differentiation in colon cancer. Cancer Res 70(4): 1469-1478

Tamman J, Ware C, Efferson C, O'neil J, Rao S, Qu X, Gorenstein J, Angagawa M, Kim H, Kenific C, Kunii K, Leach KJ, Nikov G, Zhao J, Dai X, Hardwick J, Scott M, Winter C, Bristow L, Elbi C, Reilly JF, Look T, Draetta G, Van der Ploeg LHT, Kohl NE, Strack PR, Majumder PK (2009) Down-regulation of the Notch pathway mediated by a $\gamma$-secretase inhibitor induces anti-tumour effects in mouse models of T-cell leukemia. Br J Phramacol 158(5): 1183-1195

Tanaka M, Setoguchi T, Hirotsu M, Gao H, Sasaki H, Matsunoshita Y, Komiya S (2009) Inhibition of Notch pathway prevents osteosarcoma growth by cell cycle regulation. Br J Cancer 100(12): 1957-1965

Wang J, Wakeman TP, Lathia JD, Hjelmeland AB, Wang XF, White RR, Rich JN, Sullenger BA (2010) Notch promotes radioresistance of glioma stem cells. Stem Cells 28(1): 17-28

Wang T, Holt CM, Xu C, Ridley C, P O Jones R, Baron M, Trump D (2007) Notch3 activation modulates cell growth behaviour and cross-talk to Wnt/TCF signalling pathway. Cell Signal 19(12): 2458-2467

Weinmaster G, Kopan R (2006) A garden of Notch-ly delights. Development 133(17): 3277-3282

Wilson WR, Hay MP (2011) Targeting hypoxia in cancer therapy. Nat Rev Cancer 11(6): 393-410

Zhuang HQ, Sun J, Yuan ZY, Wang J, Zhao LJ, Wang P, Ren XB, Wang CL (2009) Radiosensitizing effects of gefitinib at different administration times in vitro. Cancer Sci 100(8): 1520-1525

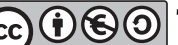

This work is licensed under the Creative Commons Attribution-NonCommercial-Share Alike 3.0 Unported License. To view a copy of this license, visit http://creativecommons. org/licenses/by-nc-sa/3.0/ 